\title{
Kolaborasi Antar Aktor Dalam Program Desa Bebas Api Di Desa Sungai Ara Kabupaten Pelalawan
}

\author{
Pesta Rida Manurung ${ }^{1}$, Dadang Mashur ${ }^{2}$ \\ 1,2,3Program Studi Ilmu Administrasi Publik, Universitas Riau \\ Email : pestarida17@gmail.com ${ }^{1}$, da2nk_mashur@yahoo.co.id ${ }^{2}$
}

Dikirim : 24 Maret 2021 | Direvisi : 07 April 2021 | Diterima : 20 Mei 2021

\begin{abstract}
ABSTRAK
Untuk ikut mengurangi tingkat kebakaran hutan dan lahan yang terus terjadi di Provinsi Riau Kabupaten Pelalawan PT Riau Andalan Pulp and Paper salah satu Pabrik kertas dan Bubur menginiasiasi Program Desa Bebas Api yang sudah berjalan selama lima tahun dibentuk tahun 2015. Program Desa Bebas Api berjalan dengan baik di salah satu Desa yang ikut program PT Riau Andalan Pulp and Paper salah satunya Desa Sungai Ara yang berhasil dibidang pertanian. Program Desa Bebas Api dikembangkan dengan lima program yaitu: Penghargaan desa bebas api, bantuan pertanian berkelanjutan, keterliban kru pemimpin dalam pencegahan kebakaran, bantuan pembukaan lahan tanpa bakar, pemantauan kualitas udara. Penelitian ini bertujuan untuk mengetahui proses kolaborasi. Penelitian menggunakan pendekatan kualitatif dengan data Deskriptif. Hasil penelitian menunjukkan bahwa pertama, Proses Kolaborasi antar Aktor dalam Program Desa Bebas Api di Desa Sungai Ara Kabupaten Pelalawan berjalan dengan baik sesuai dengan dialog tatap muka, pemahaman bersama, membangun kepercayaan, komitmen terhadap proses dan dampak sementara. Kedua, Faktor-faktor pendukung kolaborasi adalah Anggaran, ketersedian sarana dan prasarana, komunikasi dan partisipasi masyarakat.
\end{abstract}

Kata Kunci: Kolaborasi; Aktor; Program Desa Bebas Api

\section{ABSTRACT}

To help reduce the level of forest and land fires that continue to occur in Riau Province, Pelalawan Regency, PT Riau Andalan Pulp and Paper, one of the paper and pulp mills, initiated the Fire Free Village Program which has been running for five years, formed in 2015. In one of the villages that took part in the PT Riau Andalan Pulp and Paper program, one of them was Sungai Ara Village which was successful in agriculture. The Fire Free Village Program was developed with five programs, namely: Fire free village awards, sustainable agricultural assistance, involvement of the leader crew in fire prevention, assistance in clearing land without burning, monitoring air quality. This study aims to determine the process Collaboration. This research uses a qualitative approach with descriptive data. The results showed that first, the Collaboration Process between Actors in the Fire Free Village Program in Sungai Ara Village, Pelalawan Regency was running well according to face-to-face dialogue, mutual understanding, building trust, commitment to the process and temporary impacts. Second, the supporting factors for collaboration are the budget, the availability of facilities and infrastructure, communication and community participation. 
Keywords: Collaboration; Actors; Fire Free Village Program

\section{PENDAHULUAN}

Kebakaran hutan dan lahan yang sering terjadi di Indonesia disebabkan faktor kesengajaan maupun tidak, mulai dari musim kemarau yang sangat panas dan pembukaan lahan dengan cara dibakar. Di Provinsi Riau, kebakaran hutan dan lahan sering sekali terjadi yang disebabkan karena faktor kesengajaan maupun tidak sengaja (Alamsyah, 2016). Kebakaran adalah salah satu ancaman bagi pembangunan berkelanjutan negara (Hakim \& Marisa, 2021). Hal ini karena dampak negatif dari kebakaran hutan yang merusak banyak hal mulai dari ekosistem, ekonomi, sosial bahkan kesehatan banyak orang yang sering terkena infeksi saluran pernapasan (ISPA) (Adrianto et al., 2020; Prihati et al., 2018).

Menjaga kesehatan serta lingkungan sekitar dari berbagai macam sangatlah penting untuk keberlanjutan Provinsi Riau, dan kabut asap adalah salah satu masalah yang sangat fatal. Kebakaran akan menimbulkan kabut asap yang sangat berbahaya bagi kesehatan semua orang yang terkena tanpa memandang umur. Asia Pacific Resources International Holding Ltd (APRIL) adalah salah satu produsen pulp and kertas terbesar di duni. Merk unggulan mereka yang bernama "PaperOne" digunakan oleh jutaan orang untuk percetakan dan menulis setiap hari. Sebagai bentuk upaya menganggulangi kebakaran hutan dan lahan, melalui anak perusahannya yaitu PT. Riau Andalan Pulp and Paper, APRIL menginisiasi Program Desa Bebas Api. Program desa bebas api merupakan upaya perusahaan dalam mencegah kebakaran yang bertujuan untuk memberikan pengetahuan dan meningkatkan kesadaran masyarakat sekitar mengenai dampat negatif dari kebakaran lahan. APRIL juga memberikan penghargaan kepada Desa yang ikut Program desa bebas api yang tidak melakukan pembakaran untuk membersihkan lahan. Namun, penghargaan tersebut bukanlah satu-satunya yang diberikan. Program desa bebas api dikembangkan berdasarkan lima program, yaitu:

1. Penghargaan Desa Bebas Api; APRIL akan memberikan penghargaan kepada desa-desa yang berhasil mencegah kebakaran. Penghargaan tersebut diberikan dalam bentuk pembangunan infrastruktur desa senilai Rp 100 juta. Jika Desa tersebut berhasil mencegah tidak terjadinya kebakaran selama 1 tahun.

2. Bantuan Pertanian Berkelanjutan; APRIL akan memberikan bantuan peralatan pertanian kepada desa yang mengikuti program desa bebas api tujuannya untuk membantu masyarakat setempat membuka lahan tanpa melakukan pembakaran hutan dan lahan seperti tractor untuk mengelolah tanah agar bisa ditanami.

3. Keterlibatan Kru Pemimpin dalam mencegah kebakaran; Perusahaan juga memberdayakan seseorang dari desa untuk menjadi pemimpin kru. Kru pemimpin bertugas secara aktif mengkampanyekan praktik tanpa bakar lahan kepada masyarakat setempat. Kegiatan tersebut dilakukan dengan dukungan dari Kepala Desa. Lalu kru pemimpin akan mensosialisasikan kepada masyarakat desa untuk mencegah kebakaran hutan dan lahan.

4. Sosialisasi Pembukaan Lahan Tanpa Bakar; APRIL menargetkan untuk meningkatkan kesadaran masyarakat akan bahaya kebakaran hutan dan lahan maupun bahaya kabut asap untuk kesehatan, yaitu dengan Kru Pemimpin mensosialisasikan ke masyarakat dan patroli 
keliling desa yang dilaksanakan jika memasuki musim kemarau yang tujuannya memantau agar tidak terjadi kebakaran.

5. Pemantauan Kualitas Udara; APRIL menggembangkan sistem pemantauan kabut asap terpadu, berdasarkan data yang diperoleh di lapangan serta pada pengunaan peralatan canggih PM 10.

Tabel 1. Data Kebakaran Desa dalam Program Desa Bebas Api

\begin{tabular}{|c|c|c|c|c|}
\hline No & Tahun & Luasan Area (ha) & $\begin{array}{c}\text { Area Terbakar } \\
\text { (ha) }\end{array}$ & $\begin{array}{c}\text { Area terbakar } \\
\text { Berkurang }\end{array}$ \\
\hline 1 & 2014 & 352,146 & 618 & $0.18 \%$ \\
\hline 2 & 2015 & 427,876 & 54 & $0.01 \%$ \\
\hline 3 & 2016 & 592,080 & 391 & $0.07 \%$ \\
\hline 4 & 2017 & 622,112 & 159 & $0.03 \%$ \\
\hline 5 & 2018 & 622,112 & 131 & $0.02 \%$ \\
\hline 6 & 2019 & 753,604 & 2933 & $0.39 \%$ \\
\hline
\end{tabular}

Sumber: Koordinator Program Desa Bebas Api, 2020.

Berdasarkan pada tabel 1 dijelaskan data kebakaran yang terus berkurang. Hal ini berdasarkan Landscape risk map dan fire risk map yang telah dikembangkan sejak 2015. Tim RAPP memasukkan elemen-elemen mengenai resiko kebakaran lalu memasukkannya kedalam sistem informasi geografis untuk menghasilkan peta resiko kebakaran yang nantinya akan berguna sebagai titik awal dalam menentukan daerah mana yang bersiko terjadinya kebakaran hutan dan lahan. Peta ini juga di perbaruhui enam bulan sekali yang tujunnya sebagai alat strategis untuk menentukan desa mana yang akan dilibatkan dalam Program Desa Bebas Api. Program Desa Bebas Api telah berhasil meningkatkan kesadaran masyarakat sekitar akan bahaya bakar hutan dan lahan ini semua berkat kolaborasi bersama pemangku kepentingan. Salah satu desa yang ikut Program Desa bebas api yaitu Desa Sungai Ara yang berlokasi di Kecamatan Pelalawan Kabupaten Pelalawan. Untuk pertama kalinya di Desa Sungai Ara panen padi setelah ikut program desa bebas api pada tahun 2019 dengan cara membuka lahan secara alternatif dan bantuan tractor untuk membantu bercocok tanam yang diberikan PT. Riau Andalan Pulp and Paper (PT. RAPP) agar masyarakat yang ada di Desa Sungai Ara tidak membakar lahan yang dapat menyebabkan kerugian besar.

Kolaborasi pada hakikatnya adalah kerjasama yang dilakukan antar organisasi untuk mencapai tujuan bersama yang tidak mungkin dilakukan secara individu (Astari et al., 2019; Khusna, 2017). Dilihat dari implementasi program desa bebas api yang dilakukan sudah berjalan dengan baik bahkan banyak juga desa yang ikut dalam program ini dan merasakan manfaat dari program tersebut salah satunya Desa Sungai Ara yang berhasil mengikuti program desa bebas api membuka lahan tanpa membakar (Harmawan, 2017; Umar et al., 2019; Wibowo $\&$ Rostyaningsih, 2016). Ini bukan semata-mata hanya kerjasama sendiri akan tetapi adanya kolaborasi dari aktor-aktor yang terlibat baik PT. RAPP, masyarakat Desa Sungai Ara atau pihak lain yang terlibat secara langsung dalam pelaksanaan program tersebut yang bersamasama menjalin kerja sama dan komunikasi yang baik sehingga program tersebut dapat terlaksana berjalan dengan baik. Tujuan dari penelitian ini adalah untuk mengetahui proses 
kolaborasi antar aktor dalam Program Desa Bebas Api di Desa Sungai Ara Kabupaten Pelalawan dan faktor pendukung Kolaborasi.

Kolaborasi adalah proses di mana para aktor otonom atau semi otonom berinteraksi melalui negosiasi formal atau informal, secara bersama menciptakan aturan dan struktur yang mengatur hubungan mereka dan cara-cara untuk bertindak atau memutuskan masalah yang membuat mereka bersama-sama (Thompson \& Perry, 1992). Kolaborasi adalah pertukaran mengenai pandangan atau ide yang memberikan perseptif kepada seluruh kolaborator atau pihak yang terlibat (Sabaruddin, 2015). Untuk lebih memahami kolaborasi menurut Ansell \& Gash (2008, 2018), bahwa berjalannya proses kolaborasi lebih dijelaskan dalam sebuah siklus dari pada suatu proses yang bertahap. Proses kolaborasi terdiri atas beberapa komponenkomponen yang saling mempengaruhi satu sama lain, sebagai berikut:

1. Dialog tatap muka (Face to face); Kolaborasi didasarkan pada dialog tatap muka atau dialog langsung diperlukan oleh para stakeholder yang terlibat untuk saling mengenal satu dengan lainnya. Dialog tatap muka ini penting untuk dilakukan antar kolaborasi yang terlibat sehingga para stakeholder yang terlibat dapat bekerjasama sesuai dengan tujuan dan perannya masing-masing.

2. Membangun Kepercayaan (Trust Building); Membangun kepercayaan sangat perlu dilakukan para stakeholder ketika proses kolaborasi pertama kali dilakukan. Untuk itu sangat dibutuhkan pemimpin yang mampu menyadari akan pentingnya kolaborasi agar kerjasama yang dibangun bisa berjalan.

3. Komitmen terhadap Proses (Commitment to Process); Komitmen antar stakeholder sangat diperlukan untuk mencegah gagalnya kerjasama yang dijalanin. Komitmen adalah bentuk tanggung jawab stakeholder agar melihat hubungan yang dijalin dalam kolaborasi sebagai hal yang baru dan memiliki tanggung jawab harus dikembangkan.

4. Pemahaman Bersama (Shared Understanding); Setiap stakeholder yang juga terlibat dalam kolaborasi harus saling berbagi pemahaman dan pengetahuan mengenai tujuan yang ingin dicapai melalui kolaborasi. Seperti visi, misi, tujuan bersama dan lain-lain.

5. Hasil Kolaborasi (Outcome); Hasil kolaborasi dari proses kolaborasi yang terjadi. Hasil muncul apabila tujuan tersebut memberikan keuntungan dari kolaborasi baik positif maupun negatif.

\section{METODE PENELITIAN}

Metode penelitian yang digunakan adalah penelitian kualitatif dengan cara melakukan wawancara, observasi dan dokumentasi (Sugiyono, 2015). Penelitian kualitatif adalah suatu prosedur penelitian yang dilakukan tanpa adanya rekayasa dan jenis data yang dikumpulan berupa data deskriptif(Daniel, 2002). Proses penelitian kualitatif dilakukan seperti mengajukan pertanyaan-pertanyaan dan mengumpulkan data sesuai dengan informasi yang dibutuhkan (Nazir, 2003). Penelitian ini dilakukan di Desa Sungai Ara Kecamatan Pelalawan Kabupaten Pelalawan. Alasan memilih lokasi penelitian karena Desa Sungai Ara sukses dalam menerapkan Program Desa Bebas Api tanpa membakar lahan dan sukses panen padi perdana tahun 2019. Manajer Program Desa Bebas Api Bapak Sailal Arimi Koordinator Program Desa Bebas Api Ibu Riana, Camat Kecamatan Pelalawan Bapak Tangku Sakirmadan, S.Sos, Kepala Desa Sungai Ara Bapak Haryono, SE, Kru pemimpin di Desa Sungai Ara Jendri, Petani Desa 
Sungai Ara Bapak Zarkasih dan Bapak Abdul Muis, Tokoh Agama : Ustad, Pendeta, Buddha, Hindu, Tokoh Masyarakat Bapak Abdul Kadir dan Bapak Nasrun, Media Massa Halloriau dan Riauonline dan Masyarakat Setempat.

\section{HASIL DAN PEMBAHASAN}

Menurut Mia Fairuza, 2017. Kolaborasi antar Stakeholder dalam Pembangunan Inklusif pada Sektor Pariwisata (Studi Kasus Wisata Pulau Merah di Kabupaten Banyuwangi). kolaborasi antar stakeholder di pulau merah berjalan kurang baik. Hal ini ditunjukkan dari komponen kolaborasi yang mayoritas berjalan kurang baik pula. Namun, pencapaian kolaborasi dalam pembangunan inklusif tetap tercapai. Manfaat adanya wisata pulau merah telah dirasakan oleh semua pihak, termasuk pemerintah dan masyarakat sekitar. Kemudian ada Mahadin Moh. Astari, Abdul Mahsyar, Anwar Parawangi. 2019. Kolaborasi antar Organisasi Pemerintah dalam Penertiban Moda Transportasi di Kota Makassar (studi kasus kendaraan becak motor kolaborasi antara Dinas Perhubungan dan Satuan lalu lintas Polrestabes Makassar dalam penertiban kendaraan becak motor di kota Makassar. Hasil penelitian menunjukkan bahwa proses kolaborasi antara Dinas Perhubungan Kota Makassar dengan satuan lalu lintas Polrestabes Makassar tidak berjalan sesuai dengan pemahaman bersama serta dialog tatap muka hanya dilakukan di awal proses kolaborasi.

Lalu T. Anisa Pitri. 2017. Kolaborasi Pemerintah dan Masyarakat dalam Penyelenggaraan Pendidikan: Pendidikan Khusus di Provinsi Riau Tahun 2015-2016. kolaborasi pemerintah Provinsi Riau dan masyarakat dalam penyelenggaraan pendidikan khusus di tahun 2015-2016 belum berjalan dengan efektif. Masih sangat minim program yang dijalankan secara kolaborasi antara pemerintah dan masyarakat. Para aktor yang terlibat dalam penyelenggaraan pendidikan khusus di provinsi riau memainkan perannya masing-masing, namun mereka belum mampu memerankan secara optimal. Berdasarkan penelitian terdahulu diatas dapat disimpulkan pentingnya melakukan kolaborasi dengan beberapa aktor untuk menjalankan suatu program dan mencapai tujuan bersama.begitu juga dengan penelitian kolaborasi antar aktor dalam program desa bebas api di desa Sungai Ara kabupaten pelalawan perlu diadakannya kolaborasi dan melibatkan para aktor pemerintah, swasta dan masyarakat dalam menjalanan kolaborasi agar tujuan yang hendak dicapai bias berjalan dengan baik. Untuk melihat bagaimana proses kolaborasi dilakukan penulis menggunakan teori kolaborasi menurut Ansell dan Gash (Ansell \& Gash, 2008, 2018), proses kolaborasi terdiri atas beberapa komponen-komponen yang saling mempengaruhi satu sama lain, yaitu:

\section{Dialog Tatap Muka}

Kolaborasi didasarkan pada dialog tatap muka antara pemangku kepentingan. Sebagai proses yang berorientasi dialog tatap muka atau dapat disebut dialog langsung diperlukan oleh para pemangku kepetingan untuk mengidentifikasi peluang untuk keuntungan bersama. Dialog tatap muka ini penting untuk dilakukan antar kolaborasi yang terlibat sehingga para aktor yang terlibat dapat bekerjasama sesuai dengan tujuan dan fungsinya masing-masing. Dapat diketahui bahwa PT Riau Andalan Pulp and Paper melaksanakan Program Desa Bebas Api adalah bentuk upaya perusahaan dalam mengurangi tingat kebakaran hutan dan lahan dengan berkolaborasi dengan banyak aktor yang tujuannya agar banyak masyarakat yang peduli akan lingkungannya 
terutama kebakaran hutan dan lahan yang setiap tahun selalu terjadi baik karena ulah manusia maupun faktor alam. Dan seperti yang disampaikan, Manager Bapak Sailal bahwa perusahaan juga melakukan kolaborasi dengan banyak aktor terutama dengan Pemerintah Desa karena kebakaran selalu terjadi dari lahan masyarakat desa yang tujuannya agar semua masyarakat peduli akan kesehatan dan lingkungannya.

Sesuai perkataan Pak Jendri selaku kru pemimpin di Desa Sungai Ara, perusahaan merekrut seorang Kru pemimpin dari desa yang nantinya ikut juga dalam pelatihan dan pembinaan yang perusahaan adakan setiap bulannya, lalu patroli keliling desa melihat keadaan desa jika ada kebakaran yang terjadi segera mungkin melapor kepada pihak perusahaan, dan juga tokoh masyarakat dimana membantu kepala desa dan kru pemimpin dalam mengigatkan masyarakat bahaya dari membakar lahan dengan api. Perusahaan juga berkolaborasi dengan Camat Pelalawan dimana tugas Camat untuk membantu Perusahaan dalam mengarahkan setiap Desa untuk sungguh-sungguh menjaga lahannya dari kebakaran dan ikut memberikan penilaian kepada setiap desa yang berhasil. Selain itu, Perusahaan juga melibatkan pemuka agama dimana tujuannya membantu perusahaan dalam mengenalkan program desa bebas api dan memberitahu dari sekarang bahaya kebakaran menggunakan api dan juga mengajarkan hak-hal yang baik dimulai sejak sekarang. Perusahaan juga melibatkan media massa dimana perusahaan mempunyai pihak media atau Corp Comm yang bekerja sama dengan media massa dan kami juga ada akun Facebook atau Instagram yang juga bisa dilihat orang banyak.

\section{Membangun Kepercayaan}

Antar aktor perlu adanya membangun kepercayaan dilakukan ketika proses kolaborasi pertama kali dilakukan. Untuk itu diperlukan pemimpin yang mampu menyadari akan pentingnya kolaborasi agar kerjasama yang dibagun bisa berjalan. Membangun kepercayaan merupakan syarat yang sangat diperlukan dalam berkolaborasi dengan banyak aktor. Bahkan membangun kepercayaan bukanlah waktu yang singkat, dibutuhkan waktu antar aktor sebelum berkolaborasi yaitu dengan cara berkomunikasi sampai semua aktor ikut dalam kolaborasi. Begitu juga dengan PT. RAPP membangun kepercayaan para aktor juga membutuhkan waktu ke waktu tidak mudah begitu saja. Perusahaan PT RAP Membangun kepercayaan dengan semua aktor terlibat sangat susah untuk dilakukan dengan cara yaitu melakukan pendekatan terlebih dahulu, mengajak untuk berkumpul lalu pihak perusahaan sosialisasikan bahwa perusahaan PT. RAPP memiliki Program baru untuk mengurangi tingkat kebakaran yang sering terjadi dan sangat butuh bantuan dari semua pihak untuk saling bekerja sama. Begitu juga menyakinkan para petani desa yang selama ini jika ingin bertani pasti membakar lahan terlebih dahulu karena lebih mudah, tapi PT. RAPP juga memberikan bantuan pembukaan lahan 20 Ha ini juga merupakan bantuan yang PT. RAPP lakukan untuk mempermudah para petani di Desa Sungai Ara.

\section{Komitmen Pada Proses}

Komitmen antar aktor sangat diperlukan untuk mencegah gagalnya kerjasama yang dijalanin. Komitmen merupakan tanggung jawab dari stakeholder supaya memandang relasi yang dilakukan sebagai hal yang baru dan tanggung jawab tersebut perlu dikembangkan. 
Komitemen merupakan kompnen yang sangat paling penting dalam proses kolaborasi yang dilakukan, dimana perlu sekali komitmen setiap aktor yang terlibat dalam suatu program agar bisa berjalan dengan baik sesuai dengan rencana dari awal melakukan kolaborasi. PT. RAPP sangat berkomitmen dalam melaksanakan Program Desa Bebas ini sebagai bahan alternatif mengurangi tingkat kebakaran yang setiap musim kemarau selalu terjadi. Bentuk komitemen tersebut dalam bentuk pendatanganan Mou atau kesepakatan perjanjian dalam Program Desa Bebas Api yang diadakan oleh perusahaan dimana selama dua tahun akan dibina, pemberian reward kepada desa senilai RP 100 juta dalam bentuk pembangunan infrastrukur jika tidak terjadi kebakaran di desa, bahkan bantuan alat pertanian seperti traktor juga kami berikan ini wujud dari komitmen kami kepada Desa yang ikut Porgram Desa Bebas Api. Komitmen desa Sungai Ara dalam kolaborasi program desa bebas api ini sangat terbukti sekali sudah satu tahun terakhir ini tidak terjadi kebakaran apalagi pada saat keberhasilan panen padi perdana tahun 2019 semua masyarakat dan para petani juga ikut ambil bagian bekerja sama untuk mencegah kebakaran terjadi ini berkat kerja sama antara Pemerintah desa, kru pemimpin, tokoh masyarakat, para petani dan masyarakat setempat.

\section{Pemahaman Bersama}

Pemahaman bersama merupakan hal penting dalam berkolaborasi untuk mencapai tujuan. Pemahaman bersama artinya penyatuan pemikiran setiap aktor yang terlibat untuk mencegah terjadinya kesalahpaham antar aktor dalam berkolaborasi. Untuk itu sebelum melakukan kolaborasi PT. RAPP sebisa mungkin memberikan pemahaman bersama antar aktor yang terlibat agar tujuan dari kolaorasi dalam program desa bebas api bisa berjalan dengan baik seperti yang diharapkan. Dapat dipahami memberikan pemahaman bersama kepada setiap aktor dalam program desa bebas api memang sangat penting hal ini bisa mencegah terjadinya kesalahpaham antar aktor pada saat program desa bebas api berjalan, maka sebisa dan sebaik mungkin kami memberikan pemahaman ke semua aktor tentang tujuan dan fungsinya bahkan peran dari setiap actor sehingga dalam melaksakan tugasnya bias berjalan dengan baik. Seperti pemerintah desa berperan penting untuk memberikan dan mengarahkan masyarakatnya tentang bahaya kebakaran dan memperkenalkan program desa bebas api sebagai program mengurangi tingkat kebakaran hutan dan lahan, kru pemimpin mengikuti pelatihan dan pembinaan lalu sosialisasi ke masyarakat dan patroli keliling desa, tokoh masyarakat juga membantu seperti mengingatkan masyarakat bahaya kebakaran dan dampak kabut asap bagi kesehatan terutama kepada lansia dan anak-anak yang di desa.

\section{Hasil Kolaborasi}

Hasil dari proses kolaborasi terwujud dalam bentuk keluaran yang nyata. Hasil kolaborasi ini muncul apabila tujuan yang mungkin dan memberikan keuntungan dari kolaborasi yang mana secara konkrit. Dalam melakukan kolaborasi setiap aktor yang terlibat pasti akan memperoleh keuntungan dari kolaborasi yang dijalanin baik itu positif maupun negatif. Begitu juga dengan Kolaborasi antar aktor dalam program desa bebas ini semua aktor pasti memiliki dampaknya. Hasil penelitian salah satu studi sebelumnya yang mirip telah menemukan bahwa kolaborasi antar stakeholder di pulau merah berjalan kurang baik (Fairuza, 2017). Hal ini ditunjukkan dari komponen kolaborasi yang mayoritas berjalan kurang baik pula. Namun, 
pencapaian kolaborasi dalam pembangunan inklusif tetap tercapai. Manfaat adanya wisata pulau merah telah dirasakan oleh semua pihak, termasuk pemerintah dan masyarakat sekitar. Astari et al. (2019) juga telah menunjukkan bahwa kolaborasi antara Dinas Perhubungan dan Satuan lalu lintas Polrestabes Makassar dalam penertiban kendaraan becak motor di kota Makassar.

Hasil penelitian menunjukkan bahwa proses kolaborasi antara Dinas Perhubungan Kota Makassar dengan satuan lalu lintas Polrestabes Makassar tidak berjalan sesuai dengan pemahaman bersama serta dialog tatap muka hanya dilakukan di awal proses kolaborasi. Terlebih lagi, penelitian disertasi yang dilakukan oleh Pitri \& Anwar (2016) juga menunjukkan bahwa kolaborasi pemerintah Provinsi Riau dan masyarakat dalam penyelenggaraan pendidikan khusus di tahun 2015-2016 belum berjalan dengan efektif. Masih sangat minim program yang dijalankan secara kolaborasi antara pemerintah dan masyarakat. Para aktor yang terlibat dalam penyelenggaraan pendidikan khusus di provinsi riau memainkan perannya masing-masing, namun mereka belum mampu memerankan secara optimal.

Studi ini berkontribusi pada literatur dan upaya pengembangan dengan menunjukkan keuntungan-keuntungan yang didapatkan jika kolaborasi antara perusahaan dan daerah berjalan dengan baik. Bagi perusahaan yang melakukan kolaborasi dengan banyak aktor untuk membantu perusahaan dalam mengurangi tingkat kebakaran hutan dan lahan, mereka mendapatkan keuntungan berupa: (1) terciptanya lingkungan yang sehat dan bebas dari kabut asap, kesehatan nomor satu bagi kami sebagai perusahaan besar yang berproduksi dibidang kertas bagi karyawan kami jika karyawan terkena sakit maka kinerja mereka juga berkurang, bagi keluarga kami, anak-anak kami dan bagi masyarakat sekitar tentunya, dan (2) menjaga area wilayah perusahaan itu sangat penting dimana aset utama perusahaan dalam bidang produksinya adalah pohon atau kayu jika kebakaran tidak cepat dicegah maka kebakaran itu akan sampai ke area perusahaan yang nantinya dapat merugikan perusahaan.

Sedangkan keuntungan yang diperoleh Desa Sungai Ara meliputi: (1) Masyarakat Desa menjadi sehat dan terhindar dari kabut asap, menurut Bapak Haryono sebelum desa ikut program Desa Bebas Api banyak masyarakat desa yang terkena Ispa baik orang tua dan anakanak, mengganggu masyarakat desa dalam bekerja karena kebakaran di Desa Sungai Ara dulu sangat tebal kabutnya sehingga tidak banyak melakukan akivitas di luar rumah, (2) tidak ada lagi masyarakat desa yang membuka lahan dengan cara dibakar yang artinya pola pikir masyarakat mulai berubah semenjak adanya Pogram Desa Bebas Api, (3) kesadaran masyarakat semakin meningkat mengenai dampak dari kebakaran yaitu bias terkena sakit ispa, dan (4) desa juga mendapatkan reward dari perusahaan senilai RP 50 juta karena ada lahan desa yang terbakar akibat dari tetangga sebelah, yang digunakan untuk memperbaiki jalan menuju Desa Sungai Ara dan mendapatkan traktor dalam membantu para petani di desa.

\section{KESIMPULAN}

Berdasarkan hasil penelitian yang diperoleh dari lokasi penelitian dan pembahasan serta analisa yang peneliti lakukan dapat disimpulkan Kolaborasi Antar Aktor Dalam Program Desa Bebas Api Di Desa Sungai Ara Kabupaten Pelalawan sebagai berikut: Kolaborasi Antar Aktor Dalam Program Desa Bebas Api Di Desa Sungai Ara Kabupaten Pelalawan dilihat dari indikator kolaborasi menurut Ansell dan Gash yaitu: Pertama, Dialog tatap muka yang 
dilakukan secara langsung kepada setiap aktor yang terlibat dalam kolaborasi dalam program desa bebas api di Desa Sungai Ara sudah berjalan dengan baik. Kedua, Membangun kepercayaan terhadap semua aktor yang terlibat dalam mensosialisasikan dan menjelaskan tentang Program Desa Bebas Api kepada banyak masyarakat. Ketiga, Komitmen terhadap proses para aktor yang terlibat dalam Program Desa Bebas Api sudah bertanggung jawab dalam menyelesaikan tugasnya dalam menjalankan kolaborasi yang dilakukan. Keempat, Pemahaman bersama para aktor yang terlibat dalam Program Desa Api mampu memahami segala tugas dan tangung jawabnya masing-masing, memiliki tujuan yang sama yaitu mencegah terjadinya kebakaran hutan dan lahan yang menyebabkan kabut asap dan bahaya bagi kesehatan yang ada di Desa khususnya di Kabupaten Pelalawan. Kelima, Hasil Kolaborasi yaitu berjalan dengan baik dalam mensosialisasikan Program Desa Bebas Api ini kepada semua masyarakat yang ada di Desa Sungai Ara dan masyarakat yang ada di Kabupaten Pelalawan, berkurangnya kebakaran hutan dan lahan dari tahun ke tahun dan tercipnya lingkungan yang sehat tanpa kabut asap.

\section{DAFTAR PUSTAKA}

Adrianto, H. A., Spracklen, D. V., Arnold, S. R., Sitanggang, I. S., \& Syaufina, L. (2020). Forest and land fires are mainly associated with deforestation in Riau Province, Indonesia. In Remote Sensing (Vol. 12, Issue 1). https://doi.org/10.3390/RS12010003

Alamsyah, K. (2016). Kebijakan Publik, Konsep, dan Aplikasi. Media Citra Mandiri Press. Ansell, C., \& Gash, A. (2008). Collaborative governance in theory and practice. Journal of Public Administration Research and Theory, 18(4), 543-571.

Ansell, C., \& Gash, A. (2018). Collaborative platforms as a governance strategy. Journal of Public Administration Research and Theory, 28(1), 16-32.

Astari, M. M., Mahsyar, A., \& Parawangi, A. (2019). Kolaborasi Antarorganisasi Pemerintah Dalam Penertiban Moda Transportasi Di Kota Makassar (Studi Kasus Kendaraan Becak Motor). JPPM: Journal of Public Policy and Management, 1(1), 1-8.

Daniel, M. (2002). Metode penelitian sosial ekonomi. Bumi Aksara.

Emzir. (2018). Metode Penelitian Kualitatif Edisi ke-6. Rajawali Pres.

Fairuza, M. (2017). Kolaborasi antar stakeholder dalam pembangunan inklusif pada sektor pariwisata (studi kasus wisata Pulau Merah di Kabupaten Banyuwangi). Kebijakan Dan Manajemen Publik, 5(3), 1-13.

Hakim, A., \& Marisa, H. (2021). The Formation of Responsive Regional Regulations in Supporting Regional Autonomy in Pekanbaru City. JOELS: Journal of Election and Leadership, 2(1), 7-11. https://doi.org/10.31849/joels.v2i1.5884

Harmawan, B. N. (2017). Collaborative Governance Dalam Program Pengembangan Nilai Budaya Daerah Melalui Banyuwangi Ethno Carnival. Matra Pembaruan, 3(1), 57-66. https://doi.org/10.21787/mp.3.1.2019.57-66

Khusna, I. N. (2017). Dinamika Collaborative Governance Antar Stakeholder Dalam Upaya Penanggulangan HIV dan AIDS di Kabupaten Sleman. Universitas Gajah Mada.

Nazir, M. (2003). Metode Penelitian. PT. Ghalia Indonesia.

Pitri, T. A., \& Anwar, K. (2016). Kolaborasi Pemerintah Dan Masyarakat Dalam Penyelenggaraan Pendidikan: Pendidikan Khusus Di Provinsi Riau Tahun 2015-2016. 
Riau University.

Prihati, Dailiati, S., Hernimawati, \& Yandra, A. (2018). Tourism and Environmental Policy Strategies: Promoting Local Destination in Riau Province. IOP Conference Series: Earth and Environmental Science.

Sabaruddin, A. (2015). Manajemen Kolaborasi Dalam Pelayanan Publik Teori, Konsep dan Aplikasi. Graha Ilmu.

Sugiyono, P. (2015). Memahami penelitian kualitatif. Alfabeta.

Thompson, P. A., \& Perry, J. G. (1992). Engineering construction risks: A guide to project risk analysis and assessment implications for project clients and project managers. Thomas Telford.

Umar, A., Burhanuddin, B., \& Nasrulhaq, N. (2019). Kolaborasi Aktor dalam Pembangunan Pariwisata Hutan Mangrove Tongke-Tongke Kabupaten Sinjai, Sulawesi Selatan. Matra Pembaruan: Jurnal Inovasi Kebijakan, 3(1), 57-66.

Wibowo, R. F., \& Rostyaningsih, D. (2016). Analisis Aktor Implementasi Dalam Kebijakan Rencana Tata Ruang Wilayah Kota Semarang (Studi Kasus Di Kecamatan Gunungpati). Journal of Public Policy and Management Review, 5(4), 17-32. 